\title{
Prominent Clinical Dimension, Duration of Illness and Treatment Response in Schizophrenia: A Naturalistic Study
}

\author{
Massimiliano Buoli ${ }^{\bowtie}$, Alice Caldiroli, Gabriele Panza and Alfredo Carlo Altamura \\ Department of Psychiatry, University of Milan, Fondazione IRCCS Ca' Granda, Ospedale Maggiore Policlinico, Milan, Italy
}

Objective Preliminary data indicate that predominant positive symptoms are predictive of subsequent treatment response, while negative and cognitive symptoms are associated with poor outcome. Purpose of the present study was to investigate the relation between the predominant clinical dimension, duration of illness and acute antipsychotic response in a sample of schizophrenic inpatients.

Methods Fifty-one schizophrenic inpatients, receiving an antipsychotic mono-therapy, were dimensionally assessed at the admission in the Acute Psychiatric Unit of the University of Milan. Treatment response was selected as parameter of outcome and defined as a reduction $>50 \%$ of baseline total The Positive and Negative Syndrome Scale (PANSS) score. Demographic and clinical variables between responders and non-responders were compared using one-way analysis of variance for continuous variables and $\chi^{2}$ test for dichotomous ones. Binary logistic regression was performed to find if dimensional scores and duration of illness were associated with acute antipsychotic response.

Results A longer duration of illness was found in non-responders respect to responders (15.61 years vs. 8.28 years) $(\mathrm{F}=4.98, \mathrm{p}=0.03)$. Higher scores on PANSS positive sub-scale $(\mathrm{OR}=1.3, \mathrm{p}=0.03)$, lower scores on cognitive PANSS scores $(\mathrm{OR}=0.75, \mathrm{p}=0.05)$ and shorter duration of illness $(\mathrm{OR}=0.93, \mathrm{p}=0.04)$ were found to be predictive of acute antipsychotic response.

Conclusion These preliminary results show that a long duration of illness as well as a more severe cognitive impairment is predictive of treatment non-response, indicating a worse outcome for chronic patients with predominant cognitive symptoms.

Psychiatry Investig 2012;9:354-360

Key Words Schizophrenia, Clinical dimensions, Antipsychotic response.

\section{INTRODUCTION}

According to the Diagnostic and Statistical Manual for Mental Disorders (DSM) schizophrenia is a categorical condition, markedly separated from the physiological behavior of general population. ${ }^{1}$ However, in the last years, the evidence of a psychopathological "continuum" between the disorder and the general population, ${ }^{2}$ the isolation of ultra-risk populations and the multi-factorial etiology of the disorder, supported a dimensional approach. Patients diagnosed as schizophrenics, in fact, show distinct antipsychotic response and social functioning in relation to clinical presentation. ${ }^{3}$ In line with this approach, in the last years several trials have studied the relation between

Received: March 28, 2012 Revised: June 1, 2012

Accepted: June 10, 2012 Available online: November 14, 2012

$\bowtie$ Correspondence: Massimiliano Buoli, MD

Department of Psychiatry, University of Milan, Fondazione IRCCS Ca'Granda Ospedale Maggiore Policlinico, Via F. Sforza 35, 20122, Milan, Italy

Tel: +39-02-55035934, Fax: +39-02-55033190

E-mail: massimiliano.buoli@hotmail.it

(a) This is an Open Access article distributed under the terms of the Creative Commons Attribution Non-Commercial License (http://creativecommons.org/licenses/bync/3.0) which permits unrestricted non-commercial use, distribution, and reproduction in any medium, provided the original work is properly cited. the predominant symptoms and the antipsychotic response in patients affected by schizophrenia.-6

The available data indicate that a prevalence of positive symptoms is associated with good response to antipsychotic treatment. A very recent study for example showed as the response to pharmacological treatment is linearly correlated to the severity of positive symptoms. ${ }^{7}$

Negative symptoms are challenging for clinicians and they are associated with poor outcome. ${ }^{8}$ Atypical antipsychotics, particularly olanzapine and risperidone, are more efficacious respect to haloperidol in the treatment of negative symptoms. ${ }^{9}$ In addition recent studies show as aripiprazole may improve negative dimension probably for its partial agonist activity at dopamine D2 receptors. ${ }^{40-12}$ In contrast, the use of antidepressants in augmentation to antipsychotics did not show a clear improvement of negative symptoms. ${ }^{13}$

The severity of the disorganized dimension is predictive of poor outcome,${ }^{14}$ non-response to antipsychotics ${ }^{15}$ and low quality of life. ${ }^{16}$ Disorganization and positive symptoms are more responsive to first generation antipsychotics than other symptoms, although recent data show as atypical antipsychotics are 
superior to typical antipsychotics in the treatment of disorganized symptoms. ${ }^{4}$

One of the challenges of the long-term treatment of schizophrenia is the cognitive recovery or at least the maintenance of cognitive abilities. Of note, the severity of cognitive deficit is one of the most important predictor of long-term outcome in patients diagnosed with schizophrenia. ${ }^{17}$ Most of the available data seem to indicate some superiority of the atypical antipsychotics respect to first generation antipsychotics in improving cognitive symptoms of schizophrenic patients. ${ }^{18}$ However, the size of the cognitive improvement, as well as eventual differences between the single atypical antipsychotics, is still controversial. $^{19}$

The existence of an independent depressive psychopathological dimension in schizophrenics is still debated as the mood symptoms usually disappear with the improvement of positive/negative symptoms in most of patients. ${ }^{20,21}$ However, few studies have investigated the relation between depressive symptoms and outcome in schizophrenia. ${ }^{21}$ The atypical antipsychotics seem to be more effective respect to first generation antipsychotics in treating these symptoms. ${ }^{22}$

The prevalence of an impulsive-aggressive dimension is strongly associated with suicidal behaviour in schizophrenic patients. ${ }^{23}$ Several studies show as aggressive behaviour is well controlled by first generation antipsychotics, while impulsivity and suicidal behaviour are better improved by atypical antipsychotics with most of the data about clozapine. ${ }^{24}$

Finally, several studies have investigated the relation between duration of illness and treatment response in schizophrenia and most of the results show as this variable influences negatively treatment response. ${ }^{25}$

Purpose of the present study is to find an eventual association between prevalent clinical dimension and antipsychotic response in a sample of schizophrenic inpatients. The possible relation between symptomatic clusters and treatment response has a double interest regarding both for research and clinical purposes.

Concerning research: it could be helpful for assessing more homogenous samples in terms of symptoms and severity of illness; Concerning clinical practice: it should be valuable in order to detect patients requiring targeted pharmacological treatments for preventing poor outcome.

Finally other clinical and demographic variables such as duration of illness and age at onset have been taken into account to investigate the possible relation with acute antipsychotic response.

\section{METHODS}

Fifty-one patients hospitalized at the Department of Psy- chiatry of the University of Milan were included in the study.

\section{Inclusion criteria}

-A diagnosis of Schizophrenia according to DSM-IV-TR (Diagnostic and Statistical Manual for Mental Disorders-Text Revision), ${ }^{1}$

-An acute psychotic episode corresponding to a Positive and Negative Syndrome Scale (PANSS) score $>50,{ }^{26}$

-The patient had to be drug free for at least two weeks,

-Administration of the same antipsychotic mono-therapy treatment for at least one week that is considered by some authors a reasonable time to evaluate drug response. ${ }^{27}$

\section{Exclusion criteria}

-Comorbidity with mental retardation or other neurological conditions involving Central Nervous System (e.g., cerebral tumors),

-Comorbidity with medical diseases (e.g., hypothyroidism) or dysmetabolisms causing psychiatric symptoms,

-Medical comorbidity influencing the pharmacokinetics of antipsychotics (e.g., renal failure),

-Co-Administration of drugs that can significantly influence the pharmacokinetics of antipsychotics (e.g., antiretrovirals),

-Combined treatment with antidepressants, mood stabilizers, benzodiazepines,

-Pregnancy and breastfeeding.

The design of the study was naturalistic and prospective. All patients admitted at the acute psychiatric unit and fulfilling the DSM-IV-TR diagnostic criteria for schizophrenia (Structured Clinical Interview for DSM-IV Axis I) ${ }^{28}$ were included in the study. All patients provided a written informed consent for participation to the study and to have the clinical information included in their charts and derived by diagnostic interview reviewed. The Positive and Negative Syndrome Scale (PANSS), ${ }^{29}$ The Calgary Depression Scale for Schizophrenia (CDSS) ${ }^{30}$ and the Clinical Global Impression (severity of illness)(CGIs) were performed at baseline and each 3 days from the admission.

Of note the different psychopathological dimension were assessed this way:

Positive dimension: positive sub-scale PANSS,

Negative dimension: negative sub-scale PANSS,

Disorganized dimension: sum of the scores of the PANSS items conceptual disorganization (P2), difficulty in abstract thinking (N5), stereotyped thinking (N7), disorientation (G10), poor attention (G11), ${ }^{32}$

Cognitive dimension: sum of the score of the PANSS items conceptual disorganization (P2), difficulty in abstract thinking (N5), stereotyped thinking (N7), tension (G4), mannerisms and posturing (G5), poor attention (G11), lack of judgment 
and insight (G12), ${ }^{33}$

Depressive dimension: CDSS score,

Impulsive-Aggressive dimension: hostility (P7) and poor impulse control (G14) PANSS scores.

Furthermore the global severity (severity dimension) was assessed thorough the CGIs baseline scores. ${ }^{31}$

Patients that showed a reduction of at least $50 \%$ of the baseline PANSS scores after 8 days from baseline were defined as responders. ${ }^{34}$ Treatment response was selected as an outcome measure.

Descriptive analysis of the whole sample were performed.

The sample was then divided in two groups according to the acute pharmacological response and chi-square tests and oneway analysis of variance (ANOVA) were performed to compare respectively dichotomous and continuous variables between responders and non-responders.

A first binary logistic regression was performed considering psychopathological dimension scores as independent variables and antipsychotic response as dependent one.

A second binary logistic was then performed considering as independent variables age at onset and duration of illness, and antipsychotic response as dependent one.

For all the analyses, the level of statistical significance was set at 0.05 and not corrected. SPSS for Windows (version 18.0) was used as statistical program.

\section{RESULTS}

Clinical and demographic variables of the whole sample are described in Table 1.

Mean duration of antipsychotic treatment mono-therapy was 12.4 days ( \pm 6.4 days). Only 14 patients out of 51 (27.45\%) showed a response after 8 days of the prescribed antipsychotic treatment. None of non-responders after 8 days of treatment showed response later to the prescribed antipsychotic monotherapy. Non-responders did not differ from responders in terms of age $(\mathrm{F}=2.45, \mathrm{p}=0.12)$, age at onset $(\mathrm{F}=0.22, \mathrm{p}=0.64)$, number of hospitalizations $(\mathrm{F}=1.43, \mathrm{p}=0.24)$, number of attempted suicide $(\mathrm{F}=0.83, \mathrm{p}=0.37)$, duration of untreated illness $(\mathrm{F}=1.19, \mathrm{p}=0.28)$, duration of hospitalization $(\mathrm{F}=1.39, \mathrm{p}=0.24)$, duration of antipsychotic treatment mono-therapy $(\mathrm{F}=2.61$, $\mathrm{p}=0.11)$ and PANSS baseline scores $(\mathrm{F}=3.41, \mathrm{p}=0.07)$. In contrast non-responders showed a longer duration of illness respect to responders (15.61 years versus 8.28 years) $(\mathrm{F}=4.98, \mathrm{p}=$ $0.03)$.

Regarding dichotomous variables non-responders were not different from responders in terms of gender $\left(\chi^{2}=0.001, \mathrm{df}=1\right.$, $\mathrm{p}=1.00)$, diagnosis $\left(\chi^{2}=5.28, \mathrm{df}=3, \mathrm{p}=0.14\right)$, family history for psychiatric disorders $\left(\chi^{2}=7.66, \mathrm{df}=7, \mathrm{p}=0.38\right)$, the presence of abuse before the onset $\left(\chi^{2}=3.11, \mathrm{df}=1, \mathrm{p}=0.10\right)$, type of abuse before the onset $\left(\chi^{2}=5.31, \mathrm{df}=4, \mathrm{p}=0.27\right)$, the presence of polyabuse before the onset $\left(\chi^{2}=0.096, \mathrm{df}=1, \mathrm{p}=1.00\right)$, the presence of abuse after the onset $\left(\chi^{2}=3.94, \mathrm{df}=1, \mathrm{p}=0.08\right)$, type of abuse after the onset $\left(\chi^{2}=5.95, \mathrm{df}=4, \mathrm{p}=0.22\right)$, the presence of polyabuse after the onset $\left(\chi^{2}=4.01, \mathrm{df}=1, \mathrm{p}=0.07\right)$, psychiatric comorbidity before the onset $\left(\chi^{2}=3.78, \mathrm{df}=3, \mathrm{p}=0.36\right)$, psychiatric comorbidity after the onset $\left(\chi^{2}=0.39, \mathrm{df}=1, \mathrm{p}=1.00\right)$, the presence of previous suicidal attempts $\left(\chi^{2}=2.88, \mathrm{df}=1, \mathrm{p}=0.09\right)$, prescribed antipsychotic treatment $\left(\chi^{2}=9.87, \mathrm{df}=5, \mathrm{p}=0.08\right)$ (Table 2 and 3).

Table 1. Demographic and clinical variables of the whole sample

$\mathrm{N}=51$

$\mathrm{N}(\%)$ or mean \pm SD

\begin{tabular}{|c|c|}
\hline \multicolumn{2}{|l|}{ Gender } \\
\hline Male & $33(64.7)$ \\
\hline Female & $18(35.3)$ \\
\hline Age (years) & $36.76 \pm 12.14$ \\
\hline Age at onset (years) & $23.22 \pm 5.97$ \\
\hline \multicolumn{2}{|l|}{ Diagnostic subtypes } \\
\hline Paranoid & $19(37.2)$ \\
\hline Undifferentiated & $16(31.4)$ \\
\hline Disorganized & $15(29.4)$ \\
\hline Catatonic & $1(2.0)$ \\
\hline \multicolumn{2}{|l|}{ Abuse before the onset } \\
\hline No & $35(68.6)$ \\
\hline Yes & $16(31.4)$ \\
\hline Duration of illness (years) & $13.6 \pm 10.88$ \\
\hline \multicolumn{2}{|l|}{ Abuse after the onset } \\
\hline No & $36(70.6)$ \\
\hline Yes & $15(29.4)$ \\
\hline Duration of untreated illness (years) & $4.14 \pm 4.95$ \\
\hline \multicolumn{2}{|l|}{ Attempted suicides } \\
\hline No & $39(76.5)$ \\
\hline Yes & $12(23.5)$ \\
\hline Number of attempted suicides & $0.53 \pm 1.17$ \\
\hline Number of hospitalizations & $5.55 \pm 6.76$ \\
\hline \multicolumn{2}{|l|}{ Psichiatric comorbidity before the onset } \\
\hline None & $47(92.2)$ \\
\hline Panic disorder & $1(2.0)$ \\
\hline Obsessive-compulsive disorder & $2(3.8)$ \\
\hline Anorexia & $1(2.0)$ \\
\hline \multicolumn{2}{|l|}{ Psychiatric comorbidity after the onset } \\
\hline None & $50(98.0)$ \\
\hline Generalized anxiety disorder & $1(2.0)$ \\
\hline
\end{tabular}

Duration of untreated illness (DUI) was considered as the time elapsing between the onset of schizophrenic illness and the first antipsychotic treatment 
Table 2. Demographic and clinical variables in responders and non-responders to the antipsychotic treatment

\begin{tabular}{|c|c|c|}
\hline & Non-responders $(\mathrm{N}=37)$ & Responders $(\mathrm{N}=14)$ \\
\hline & $\mathrm{N}(\%)$ or mean $\pm \mathrm{SD}$ & $\mathrm{N}(\%)$ or mean $\pm \mathrm{SD}$ \\
\hline \multicolumn{3}{|l|}{ Gender } \\
\hline Male & $24(64.7)$ & $9(64.3)$ \\
\hline Female & $13(35.3)$ & $5(35.7)$ \\
\hline Age (years) & $38.38 \pm 11.93$ & $32.5 \pm 12.05$ \\
\hline Age at onset (years) & $22.97 \pm 6.01$ & $23.86 \pm 6.05$ \\
\hline \multicolumn{3}{|l|}{ Diagnosis (subtypes) } \\
\hline Paranoid & $12(32.4)$ & $7(50.0)$ \\
\hline Undifferentiated & $10(27.0)$ & $6(42.9)$ \\
\hline Disorganized & $14(37.8)$ & $1(7.1)$ \\
\hline Catatonic & $1(2.8)$ & $0(0.0)$ \\
\hline \multicolumn{3}{|l|}{ Abuse before the onset } \\
\hline No & $28(75.7)$ & $7(50.0)$ \\
\hline Yes & $9(24.3)$ & $7(50.0)$ \\
\hline Duration of illness (years)* & $15.62 \pm 11.1$ & $8.28 \pm 8.51$ \\
\hline \multicolumn{3}{|l|}{ Abuse after the onset } \\
\hline No & $29(78.4)$ & $7(50.0)$ \\
\hline Yes & $8(21.6)$ & $7(50.0)$ \\
\hline Duration of untreated illness (years) & $4.60 \pm 5.34$ & $2.91 \pm 3.57$ \\
\hline \multicolumn{3}{|l|}{ Attempted suicide } \\
\hline No & $26(70.3)$ & $13(92.9)$ \\
\hline Yes & $11(29.7)$ & $1(7.1)$ \\
\hline Number of attempted suicides & $0.62 \pm 1.21$ & $0.29 \pm 1.07$ \\
\hline Number of hospitalizations & $6.24 \pm 7.63$ & $3.71 \pm 3.12$ \\
\hline \multicolumn{3}{|l|}{ Psychiatric comorbidity before the onset } \\
\hline None & $34(91.9)$ & $13(92.9)$ \\
\hline Panic disorder & $0(0.0)$ & $1(7.1)$ \\
\hline Obsessive-compulsive disorder & $2(5.4)$ & $0(0.0)$ \\
\hline Anorexia & $1(2.7)$ & $0(0.0)$ \\
\hline \multicolumn{3}{|l|}{ Psychiatric comorbidity after the onset } \\
\hline None & $36(97.3)$ & $14(100.0)$ \\
\hline Generalized anxiety disorder & $1(2.7)$ & $0(0.0)$ \\
\hline
\end{tabular}

*statistics: $\mathrm{F}=4.98, \mathrm{p}=0.03$; Duration of untreated illness (DUI) was considered as the time elapsing between the onset of schizophrenic illness and the first antipsychotic treatment

The goodness-of-fit test results (Hosmer and Lemeshow Test: $\chi^{2}=3.08, \mathrm{df}=8, \mathrm{p}=0.93$ ) showed that the model including the baseline dimensional scores as possible predictors of response was adequate, allowing for a correct classification of $80.4 \%$ of the cases. In addition, the model was overall significant (Omnibus test: $\chi^{2}=20.65, \mathrm{df}=8, \mathrm{p}=0.008$ ). Higher scores of dyscognitive dimension $(\mathrm{OR}=0.75, \mathrm{p}=0.05)$ and $\mathrm{CGIs}(\mathrm{OR}=$ $0.16, \mathrm{p}=0.04)$ were predictive of non-response. In contrast higher scores of positive dimension were predictive of response to antipsychotics ( $\mathrm{OR}=1.23, \mathrm{p}=0.028)$ (Table 4, Figures 1 and 2).

The goodness-of-fit test results (Hosmer and Lemeshow
Test: $\chi^{2}=8.74, \mathrm{df}=8, \mathrm{p}=0.36$ ) showed that the model including duration of illness and age at onset as possible predictors of antipsychotic response was adequate, allowing for a correct classification of $72.5 \%$ of the cases. In addition the model was nearly statistically significant (Omnibus test: $\chi^{2}=5.40, \mathrm{df}=2, \mathrm{p}=$ $0.06)$. A longer duration of illness was found to be predictive of non-response $(\mathrm{OR}=0.93, \mathrm{p}=0.04)$ (Table 5).

\section{DISCUSSION}

The first datum emerging from this study is that only $27.45 \%$ 
Table 3. Mean dosages of prescribed antipsychotics in responders and non-responders (chlorpromazine milliequivalents)

\begin{tabular}{lcc}
\hline Antipsychotic & $\begin{array}{c}\text { Non-responders } \\
(\mathrm{N}=37)\end{array}$ & $\begin{array}{c}\text { Responders } \\
(\mathrm{N}=14)\end{array}$ \\
\hline Quetiapine & 763 & 435 \\
Olanzapine & 535 & 560 \\
Risperidone & 200 & 270 \\
Aripiprazole & 312 & 133 \\
Zuclopentixole & 243 & - \\
Haloperidol & 225 & 150 \\
\hline
\end{tabular}

Table 4. Summary of the statistics for the best-fit logistic regression model applied (baseline dimensional scores)

\begin{tabular}{lcccccc}
\hline $\begin{array}{c}\text { Baseline dimensional } \\
\text { scores }\end{array}$ & B & S.E. & Wald & df & p & $\begin{array}{c}\text { Exp } \\
\text { (B) }\end{array}$ \\
\hline Positive & 0.205 & 0.093 & 4.856 & 1 & 0.028 & 1.227 \\
Negative & 0.084 & 0.078 & 1.162 & 1 & 0.281 & 1.087 \\
Disorganized & -0.210 & 0.147 & 2.035 & 1 & 0.154 & 0.810 \\
Cognitive & -0.283 & 0.144 & 3.873 & 1 & 0.05 & 0.754 \\
Depressive & 0.005 & 0.214 & 0.001 & 1 & 0.981 & 1.005 \\
Hostility & 0.990 & 0.649 & 2.324 & 1 & 0.127 & 2.691 \\
Impulsivity & -0.174 & 0.291 & 0.357 & 1 & 0.55 & 0.840 \\
Severity (CGIs) & -1.812 & 0.897 & 4.082 & 1 & 0.04 & 0.163 \\
\hline
\end{tabular}

In this analysis the dependent variable was the antipsychotic response. B: coefficient, SE: standard error of B, Wald: Wald statistics, df: degree of freedom, p: significance, $\operatorname{Exp}(\mathrm{B})$ : odds ratio. Omnibus Test of Model Coefficients: $\chi^{2}=20.65, \mathrm{df}=8, \mathrm{p}=0.008$

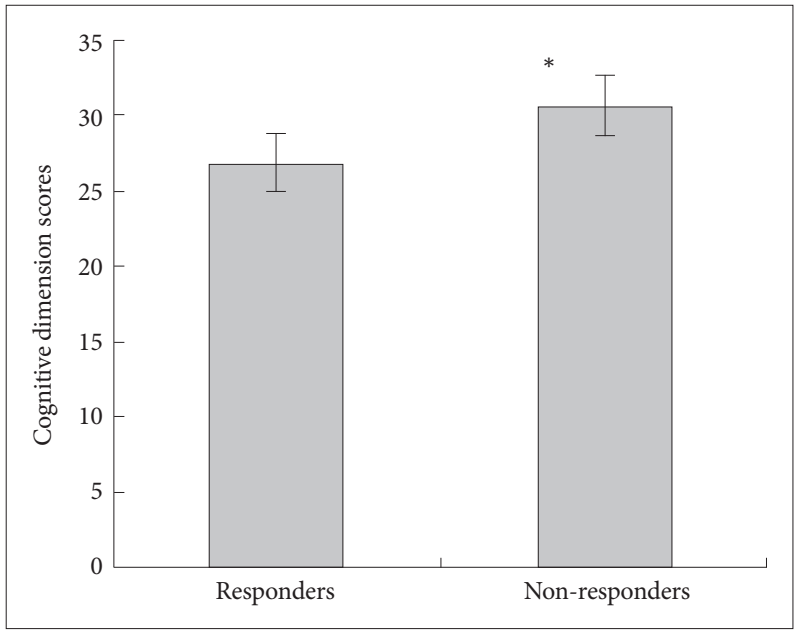

Figure 1. Baseline cognitive dimension scores and acute antipsychotic response. *statistics: $\mathrm{F}=6.82, \mathrm{p}=0.012$.

of schizophrenic inpatients have a response to antipsychotics in agreement with a relatively recent study. ${ }^{9}$ Secondly, cognitive impairment and global severity of illness seem to be predictive of lack of response to antipsychotics, while positive dimension would be associated with good acute treatment response. Regarding the possible relation between clinical vari-

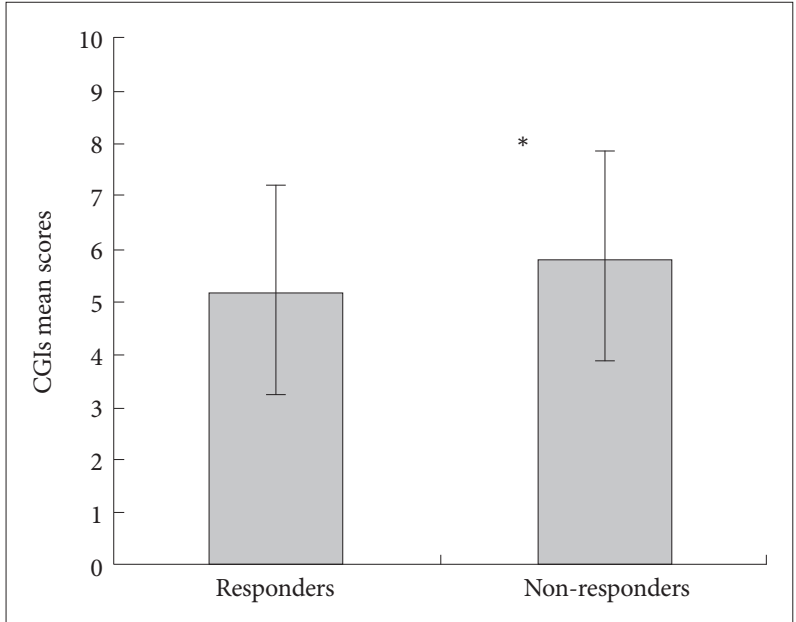

Figure 2. Clinical Global Impression Severity of Illness (CGIs) baseline scores and acute antipsychotic response. *statistics: $\mathrm{F}=$ $7.34, p=0.009$

Table 5. Summary of the statistics for the best-fit logistic regression model applied (age at onset/duration of illness)

\begin{tabular}{lcccccc}
\hline Clinical variables & B & S.E. & Wald & df & $p$ & $\operatorname{Exp~(B)~}$ \\
\hline Age at onset & -0.023 & 0.057 & 0.155 & 1 & 0.693 & 1.023 \\
Duration of illness & -0.076 & 0.037 & 4.216 & 1 & 0.040 & 0.926
\end{tabular}

In this analysis the dependent variable was the antipsychotic response. B: coefficient, SE: standard error of B, Wald: Wald statistics, df: degree of freedom, p: significance, $\operatorname{Exp}(B)$ : odds ratio. Omnibus Test of Model Coefficients: $\chi^{2}=5.40, \mathrm{df}=2, \mathrm{p}=0.06$

ables and outcome, duration of illness seems to be predictive of antipsychotic response. Of note patients with long duration of illness seem to be less respondent to acute antipsychotic treatment respect to patients with a short one. Taken as a whole these results show as chronic patients with cognitive impairment are the most challenging for the clinicians, while patients with a short duration of illness and predominant positive symptoms present the best treatment response. In light of these considerations the low rate of response in our sample could be partially explained by the mean long duration of illness of our sample (13.6 years).

Previous studies have already showed as cognitive impairment and long duration of illness are associated with poor outcome ${ }^{17}$ while predominant positive symptoms are associated with good prognosis. ${ }^{7}$ Of note chronic patients with cognitive impairments are likely to show compromised magnetic resonance (MR) images associated with scarce response to antipsychotic treatment. $^{35}$

Atypical antipsychotics probably prevent the negative effects of duration of illness ${ }^{36}$ so that primary (recognition and treatment of ultra risk populations) and secondary (early treatment with atypical antipsychotics) prevention strategies could be perhaps the most appropriate strategies to improve outcome of schizophrenic patients. ${ }^{37}$ 
The future research should have two main objectives:

1) an accurate evaluation of the impact of a specific symptomatic dimension on the outcome of schizophrenic patients,

2) to investigate the effect of the pharmacological treatment on the biological factors (e.g. neurodegeneration) involved in "resistant" patients with poor response to antipsychotics. ${ }^{38}$

Finally the predominant symptomatic dimension as a specific predictor of outcome should be introduced in the current diagnostic classifications (DSM and International Classification Disease-ICD).

The limits of the present study have to be shortly described. First the sample size is small and heterogeneous as multiple antipsychotics were prescribed. Of note, the variability of the antipsychotic treatment has to be taken into account although no differences were found between responders and non-responders. Second confounding factors like the time of evaluation of response (8 days from baseline) or the number of previous trials with typical antipsychotics, supposedly affecting negative and cognitive dimensions, are to be taken into consideration. However, as reported in the results none of the nonresponders showed response later. In contrast to these limits the study design is naturalistic and prospective with the advantage to be close to the clinical practice. In addition in authors' knowledge no studies have considered all clinical dimensions, including the depressive one, to predict acute treatment response in schizophrenic patients. Studies with larger and homogenous samples are needed to confirm these results

\section{Acknowledgments}

Drs Buoli, Caldiroli and Panza do not have any affiliation with or financial interest in any organization that might pose a conflict of interest with the present article.

Prof. A. Carlo Altamura is:

- Merck consultant,

- Astra Zeneca consultant,

- Sanofi-Aventis speaker bureau,

- Lilly speaker bureau,

- Pfizer speaker bureau.

The paper was funded by TR29 Innovation Programme provided by Lombardy government. The authors express a special appreciation to Lombardy government for the interest and financial support of the present research.

\section{REFERENCES}

1. American Psychiatric Association. Diagnostic and Statistical Manual of Mental Disorders, 4th Edition. Text Revision. American Psychiatric Association; 2000.

2. Kaiser S, Heekeren K, Simon JJ. The negative symptoms of schizophrenia: category or continuum? Psychopathology 2011;44:345-353.

3. Altamura AC, Bobo WV, Meltzer HY. Factors affecting outcome in schizophrenia and their relevance for psychopharmacological treatment. Int Clin Psychopharmacol 2007;22:249-267.

4. Janicak PG, Glick ID, Marder SR, Crandall DT, McQuade RD, Marcus $\mathrm{RN}$, et al. The acute efficacy of aripiprazole across the symptom spectrum of schizophrenia: a pooled post hoc analysis from 5 short-term studies. J Clin Psychiatry 2009;70:25-35.
5. Riedel M, Spellmann I, Strassnig M, Douhet A, Dehning S, Opgen-Rhein $\mathrm{M}$, et al. Effects of risperidone and quetiapine on cognition in patients with schizophrenia and predominantly negative symptoms. Eur Arch Psychiatry Clin Neurosci 2007;257:360-370.

6. Canuso CM, Bossie CA, Turkoz I, Alphs L. Paliperidone extended-release for schizophrenia: effects on symptoms and functioning in acutely ill patients with negative symptoms. Schizophr Res 2009;113:56-64.

7. Schennach-Wolff R, Jäger M, Mayr A, Meyer S, Kühn KU, Klingberg S, et al. Predictors of response and remission in the acute treatment of firstepisode schizophrenia patients-- is it all about early response? Eur Neuropsychopharmacol 2011;21:370-378.

8. Malla A, Payne J. First-episode psychosis: psychopathology, quality of life, and functional outcome. Schizophr Bull 2005;31:650-671.

9. Green AI, Tohen MF, Hamer RM, Strakowski SM, Lieberman JA, Glick I, et al. First episode schizophrenia-related psychosis and substance use disorders: acute response to olanzapine and haloperidol. Schizophr Res 2004;66:125-135.

10. Swainston Harrison T, Perry CM. Aripiprazole: a review of its use in schizophrenia and schizoaffective disorder. Drugs 2004;64:1715-1736.

11. Kane JM, Assunção-Talbott S, Eudicone JM, Pikalov A, Whitehead R, Crandall DT. The efficacy of aripiprazole in the treatment of multiple symptom domains in patients with acute schizophrenia: a pooled analysis of data from the pivotal trials. Schizophr Res 2008;105:208-215.

12. Chang JS, Ahn YM, Park HJ, Lee KY, Kim SH, Kang UG, et al. Aripiprazole augmentation in clozapine-treated patients with refractory schizophrenia: an 8-week, randomized, double-blind, placebo-controlled trial. J Clin Psychiatry 2008;69:720-731.

13. Goodwin G, Fleischhacker W, Arango C, Baumann P, Davidson M, de Hert M, et al. Advantages and disadvantages of combination treatment with antipsychotics ECNP Consensus Meeting, March 2008, Nice. Eur Neuropsychopharmacol 2009;19:520-532.

14. Salokangas RK, Honkonen T, Stengård E, Koivisto AM. Symptom dimensions and their association with outcome and treatment setting in long-term schizophrenia. Results of the DSP project. Nord J Psychiatry 2002;56:319-327.

15. Robinson DG, Woerner MG, Alvir JM, Geisler S, Koreen A, Sheitman B, et al. Predictors of treatment response from a first episode of schizophrenia or schizoaffective disorder. Am J Psychiatry 1999;156:544-549.

16. Breier A, Berg PH. The psychosis of schizophrenia: prevalence, response to atypical antipsychotics, and prediction of outcome. Biol Psychiatry 1999;46:361-364.

17. Weiss EM, Bilder RM, Fleischhacker WW. The effects of second-generation antipsychotics on cognitive functioning and psychosocial outcome in schizophrenia. Psychopharmacology (Berl) 2002;162:11-17.

18. Bilder RM, Goldman RS, Volavka J, Czobor P, Hoptman M, Sheitman B, et al. Neurocognitive effects of clozapine, olanzapine, risperidone, and haloperidol in patients with chronic schizophrenia or schizoaffective disorder. Am J Psychiatry 2002;159:1018-1028.

19. Goldberg TE, Goldman RS, Burdick KE, Malhotra AK, Lencz T, Patel $\mathrm{RC}$, et al. Cognitive improvement after treatment with second-generation antipsychotic medications in first-episode schizophrenia: is it a practice effect? Arch Gen Psychiatry 2007;64:1115-1122.

20. Jäger M, Riedel M, Schmauss M, Pfeiffer H, Laux G, Naber D, et al. Depression during an acute episode of schizophrenia or schizophreniform disorder and its impact on treatment response. Psychiatry Res 2008;158: 297-305.

21. Koreen AR, Siris SG, Chakos M, Alvir J, Mayerhoff D, Lieberman J. Depression in first-episode schizophrenia. Am J Psychiatry 1993;150: 1643-1648.

22. Mauri MC, Moliterno D, Rossattini M, Colasanti A. Depression in schizophrenia: comparison of first- and second-generation antipsychotic drugs. Schizophr Res 2008;99:7-12.

23. Altamura AC, Bassetti R, Bignotti S, Pioli R, Mundo E. Clinical variables related to suicide attempts in schizophrenic patients: a retrospective study. Schizophr Res 2003;60:47-55. 
24. Meltzer HY, Alphs L, Green AI, Altamura AC, Anand R, Bertoldi A, et al. Clozapine treatment for suicidality in schizophrenia: International Suicide Prevention Trial (InterSePT). Arch Gen Psychiatry 2003;60:82-91.

25. Altamura AC, Buoli M, Serati M. Duration of illness and duration of untreated illness in relation to drug response in psychiatric disorders. Neuropsychiatry 2011;1:81-90.

26. Mu Q, Johnson K, Morgan PS, Grenesko EL, Molnar CE, Anderson B, et al. A single $20 \mathrm{mg}$ dose of the full D1 dopamine agonist dihydrexidine (DAR-0100) increases prefrontal perfusion in schizophrenia. Schizophr Res 2007;94:332-341.

27. Agid O, Seeman P, Kapur S. The "delayed onset" of antipsychotic action-an idea whose time has come and gone. J Psychiatry Neurosci 2006; 31:93-100.

28. First MB, Spitzer RL, Gibbon M, Williams JBW. Structured Clinical Interview for DSM-IV Axis I (SCID-I), Clinician Version. Washington, DC: American Psychiatric Press; 1997.

29. Kay SR, Fiszbein A, Opler LA. The positive and negative syndrome scale (PANSS) for schizophrenia. Schizophr Bull 1987;13:261-276.

30. Addington D, Addington J, Schissel B. A depression rating scale for schizophrenics. Schizophr Res 1990;3:247-251.

31. Guy W. ECDEU Assessment Manual for Psychopharmacology. Rockville, MD: US Department of Health, Education and Welfare; 1976.
32. Monteiro LC, Silva VA, Louzã MR. Insight, cognitive dysfunction and symptomatology in schizophrenia. Eur Arch Psychiatry Clin Neurosci 2008;258:402-405.

33. Bell MD, Lysaker PH, Milstein RM, Beam-Goulet JL. Concurrent validity of the cognitive component of schizophrenia: relationship of PANSS scores to neuropsychological assessments. Psychiatry Res 1994;54:51-58.

34. Leucht S, Davis JM, Engel RR, Kissling W, Kane JM. Definitions of response and remission in schizophrenia: recommendations for their use and their presentation. Acta Psychiatr Scand Suppl 2009;438:7-14.

35. Schimmelmann BG, Huber CG, Lambert M, Cotton S, McGorry PD, Conus P. Impact of duration of untreated psychosis on pre-treatment, baseline, and outcome characteristics in an epidemiological first-episode psychosis cohort. J Psychiatr Res 2008;42:982-990.

36. van Haren NE, Hulshoff Pol HE, Schnack HG, Cahn W, Mandl RC, Collins DL, et al. Focal gray matter changes in schizophrenia across the course of the illness: a 5-year follow-up study. Neuropsychopharmacology 2007;32:2057-2066.

37. McGorry PD. The nature of schizophrenia: signposts to prevention. Aust N Z J Psychiatry 2000;34(suppl):S14-S21.

38. Altamura AC, Glick ID. Designing outcome studies to determine efficacy and safety of antipsychotics for 'real world' treatment of schizophrenia. Int J Neuropsychopharmacol 2010;13:971-973. 